\title{
УДК 378.14:004.9
}

\section{Петков Александр Александрович}

старший научный сотрудник, доктор технических наук, ведущий научный сотрудник, доцент кафедры «Инженерная электрофизика»

Научно-исследовательский и проектно-конструкторский институт «Молния» Национального технического университета «Харьковский политехнический институт» г. Харьков, Украина apetkov@yandex.ru

\section{ПЕДАГОГИЧЕСКИЕ ВОЗМОЖНОСТИ ТЕСТОВ С ВОССТАНАВЛИВАЕМЫМИ ФРАГМЕНТАМИ}

\begin{abstract}
Аннотация. В статье рассмотрены педагогические возможности тестов, которые формируются по методу восстанавливаемых фрагментов. Проведен анализ взаимосвязи тестов данного типа с другими типами тестов. Показана возможность применения тестов с восстанавливаемыми фрагментами для контроля усвоения на уровне воспроизведения: языковых выражений, представленных в текстовом формате, набора символов, имеющих смысловую нагрузку, а также языковых выражений, которые описывают графически представленные объекты. Приведены результаты экспериментов, которые подтверждают возможность использования тестов с восстанавливаемыми фрагментами для контроля усвоения теоретического материала, обучения и стимулирования учебной деятельности студентов.
\end{abstract}

Ключевые слова: тест с восстанавливаемыми фрагментами; педагогические возможности; языковые выражения; контроль усвоения; обучение; стимулирование учебной деятельности.

\section{1. ВВЕДЕНИЕ}

Общество, выделив средства на обучение специалиста (не важно, платит ли студент за обучение или получает стипендию), вправе иметь гарантии того, что эти средства затрачены не впустую. На начальных этапах обучения такой гарантией выступает оценка успешности усвоения изученного материала. Получению полной и объективной оценки такого рода способствуют новые информационные технологии, внедряемые в учебный процесс.

Постановка проблемы. Студенты, изучившие конкретный учебный курс, должны обладать знаниями минимум на уровне воспроизведения [1]. Только это позволит переходить к изучению других предметов, материал которых базируется на данной изученной области знаний, использовать знания в практической деятельности и в дальнейшем, при необходимости, продолжить образование в изученной области знаний. Согласно [1] уровень воспроизведения характеризуется тем, что «обучаемый способен воспроизводить определения понятий, формулировки законов, характеристики материальных и идеальных объектов в устной и письменной форме», то есть «всех сведений, которые необходимо запомнить и воспроизвести» [2]. Таким образом, значительная часть знаний, которые подлежат изучению в процессе профессионального обучения специалистов, представляет собой языковые выражения [3]. Традиционные формы контроля - зачет и устный экзамен, которые являются наиболее активной и обстоятельной формой проверки знаний, в том числе представленных в виде языковых выражений, в разумных временных рамках не обеспечивают достоверный контроль знаний и требуют перехода к компьютеризированному тестовому контролю. 
Анализ последних исследований и публикаций. В настоящее время, по одной из версий классификации, тестовые задания подразделяются на две группы: тестовые задания закрытого типа, которые сопровождаются готовыми вариантами ответов, и тестовые задания открытого типа, которые предполагают вариант ответа респондента [4-6]. На рис. 1 показана взаимосвязь тестов: традиционных типов (блок 1 и блок 2), тестов с восстанавливаемыми фрагментами (ТВФ) [3; 7] (блок 3) и перспективных тестов (блок 4), которые будут разработаны при достаточном уровне развития компьютерной техники.

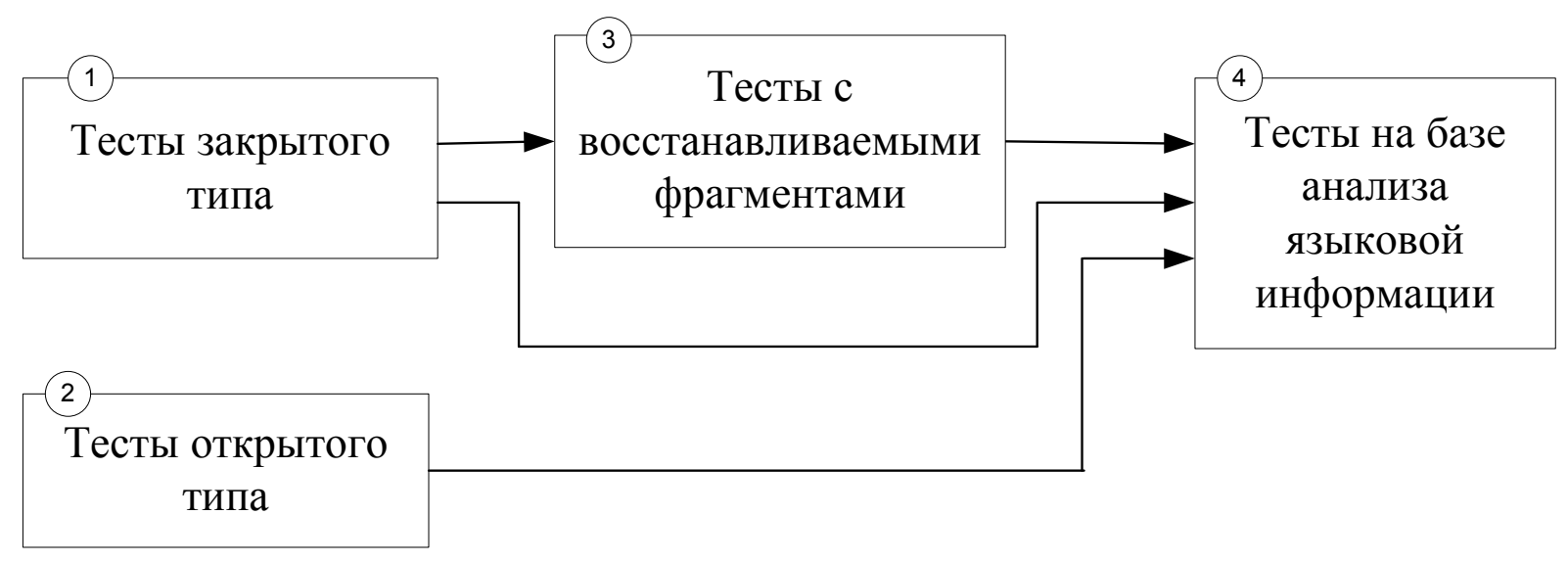

Рис. 1. Взаимосвязь компьютерных тестов различных типов

Рассмотрим особенности конструирования и применения основных типов компьютерных тестов, которые обеспечивают оценку уровня усвоения языковых выражений.

На сегодняшний день тесты закрытого типа (рис. 1, блок 1) являются наиболее распространенными тестами контроля знаний. Программирование тестов закрытого типа обеспечивают как имеющиеся программные приложения компьютеров, так и специально разработанные компьютерные программы. Однако кажущаяся простота подготовки контрольного материала тестов и доступность программного обеспечения часто играют злую шутку с непрофессиональными создателями тестов - в большинстве случаев они получают тесты низкого качества. Это еще раз подтверждает известный тезис, что «широке використання тестових технологій - це дійсно інша культура освітнього процесу» [4], а, значит, разработкой тестов должны заниматься специалисты, которые обучены этой культуре и применяют ее. Но несмотря на недостатки тестов данного типа [6], при их квалифицированном конструировании обеспечивается разработка высококачественных тестов, занимающих свою нишу в учебном процессе, например, задания на распознавание, классификацию, установление соответствия и др. При определенной подготовке контрольного материала тесты закрытого типа могут быть применены для косвенной оценки уровня усвоения языковых выражений, являющихся составляющими понятийно-категориального аппарата различных областей знаний [3]. Например, может быть сформулировано задание на выбор базовых терминов, входящих в определение понятий, формулировки теорем, законов и т. п. Однако для оценки целесообразности применения тестов в этом случае необходим тщательный анализ их надежности и валидности [8].

Тесты открытого типа (рис. 1, блок 2) обеспечивают более широкие возможности при контроле усвоения теоретического материала, но они более сложны в обработке ответов респондентов. Для компьютерной обработки тестов открытого типа в общем случае необходимо выполнение, как минимум, следующих требований: 
1) вводимая информация должна распознаваться компьютерной программой, реализующей тест, то есть программа должна «понимать» - что введено (символ, рисунок, текстовое выражение и т. д.);

2) программа должна быть способна «очистить» введенную информацию от грубых ошибок, не влияющих на суть ответа;

3) программа должна быть способна сравнить введенную информацию с шаблоном и делать заключение о достоверности ответа (или его близости к шаблону).

Реализация указанных функций в общем случае достаточно сложна, но все же обеспечивается современным уровнем развития компьютерной техники и программного обеспечения.

Тесты открытого типа также могут быть использованы для оценки усвоения знаний, представленных в виде языковых выражений, например, в виде заданий на заполнение пропусков в предъявленном тексте. Целесообразность применения таких тестов также определяется в первую очередь их надежностью и валидностью.

ТВФ (рис. 1, блок 3) являются развитием тестов закрытого типа, а именно, тестов с множественным выбором, от которых отличаются тем, что в качестве реакции компьютерной программы при выборе верного варианта (из множества предъявленных вариантов) визуально восстанавливается часть языкового выражения, которая используется респондентом в дальнейшей учебной деятельности по формированию ответа [7].

Тесты, формируемые на базе анализа речевой информации (рис. 1, блок 4) - это средство компьютерного анализа речевого воспроизведения языковых выражений, представленных в звуковом или текстовом формате. В настоящее время, несмотря на успехи в разработке искусственного интеллекта, тесты данного класса еще не достигли уровня практического использования в системе образования [9].

Таким образом, ТВФ, являющиеся промежуточным этапом на пути к полной интеллектуализации процесса контроля знаний, на современном уровне развития компьютерной техники представляют собой оптимальный вариант тестов, которые позволяют контролировать усвоение языковых выражений на уровне воспроизведения.

ТВФ, как и любое средство, используемое в педагогической деятельности, обладают рядом возможностей, обуславливающих их применение. Однако в известных информационных источниках отсутствует детальное рассмотрение и особенности использования педагогических возможностей ТВФ.

Цель статьи. Исследование педагогических возможностей компьютерных тестов, которые создаются с использованием метода восстанавливаемых фрагментов и особенностей их применения для контроля различных видов (представлений) знаний.

\section{2. МЕТОДЫ ИССЛЕДОВАНИЯ}

Исследования проводились в рамках оценивания перспективности использования тестов с восстанавливаемыми фрагментами в практике подготовки специалистов электротехнического профиля.

В процессе исследований использовались следующие методы: анализ теоретических источников по проблеме методической подготовки тестовых заданий; проведение педагогических экспериментов; статистическая обработка, обобщение и оценивание результатов. 


\section{3. РЕЗУЛЬТАТЫ ИССЛЕДОВАНИЯ}

В отличие от традиционных тестов (рис. 1, блок 1 и блок 2), ТВФ могут быть реализованы только с использованием компьютерной техники. Причем программирование ТВФ осуществляется с помощью специализированного программного обеспечения [10]. Этот факт нашел отражение в комплексе педагогических возможностей, которыми обладают ТВФ.

Как было показано выше, основной педагогической возможностью, предоставляемой ТВФ, является контроль усвоения теоретического материала на уровне воспроизведения (рис. 2). Сюда в первую очередь относится контроль усвоения языковых выражений, представленных в текстовом формате [3; 7].

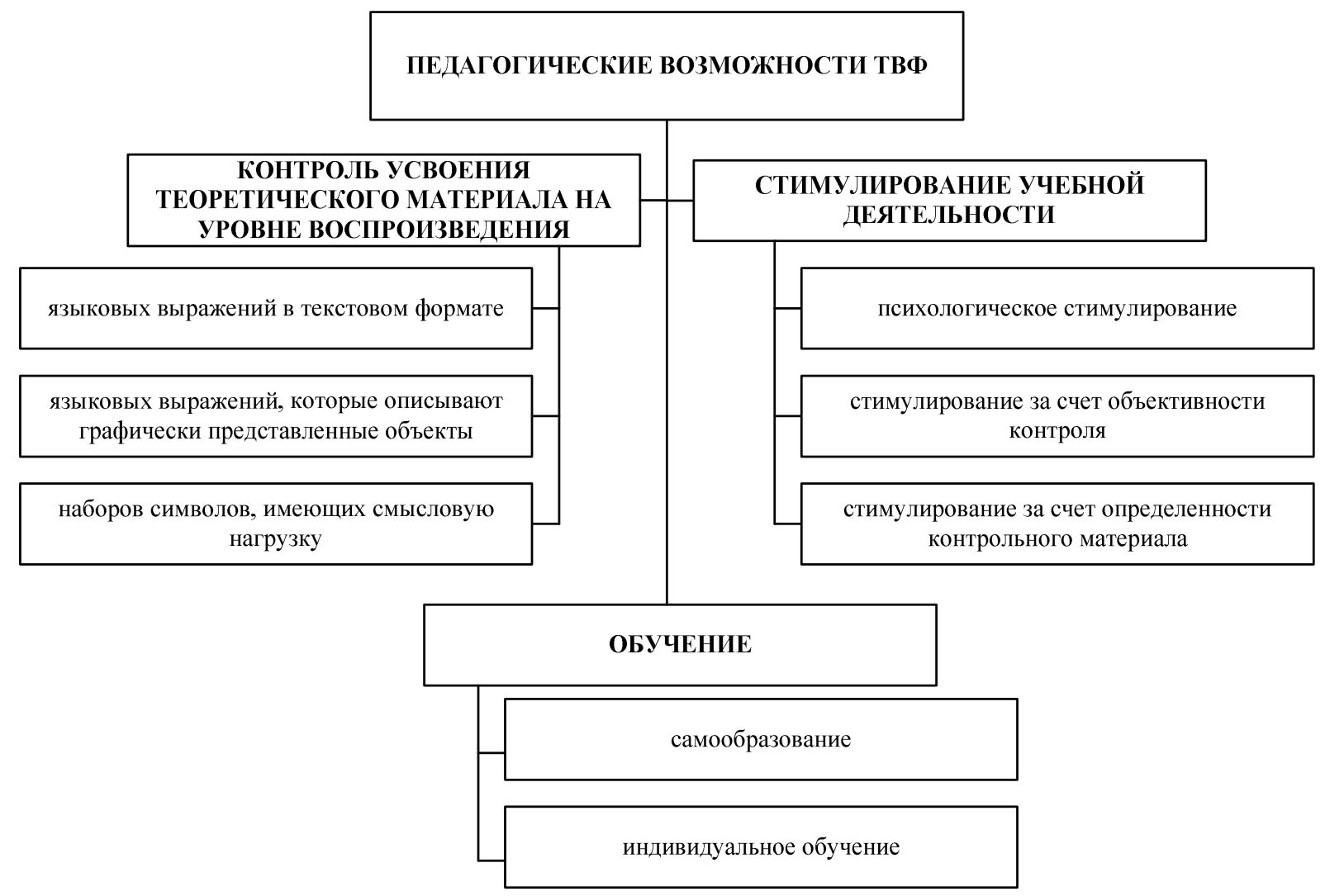

Рис. 2. Структура педагогических возможностей ТВФ

Существенно расширить базу контролируемых материалов возможно путем использования тестов совместно с графическими материалами, на которых изображаются объекты, описываемые контролируемыми языковыми выражениями. В этом случае ТВФ могут использоваться, например, при изучении структуры технических устройств. В [11] автором описан опыт применения ТВФ для контроля усвоения студентами структуры и работы высоковольтного генератора импульсов напряжения. Особенностью контроля в этом случае явилось то, что студентам предоставлялась схема генератора, элементы которой были обозначены порядковыми номерами, и все задания формулировались с использованием этих номеров. 
В качестве предметов контроля может использоваться также набор символов, обладающих смысловой нагрузкой, например, описание выходной функции объекта исследования при планировании экспериментов типа ПФЭ $2^{3}$ полиномом вида [12]:

$$
y=b_{0}+b_{1} x_{1}+b_{2} x_{2}+b_{3} x_{3}+b_{12} x_{1} x_{2}+b_{13} x_{1} x_{3}+b_{23} x_{2} x_{3}+b_{123} x_{1} x_{2} x_{3} .
$$

При этом в качестве верных элементов набора для выбора используются члены полинома вида $b_{0}+, b_{1} x_{1}+, b_{2} x_{2}+b_{3} x_{3}+, b_{12} x_{1} x_{2}+, b_{13} x_{1} x_{3}+, b_{23} x_{2} x_{3}+, b_{123} x_{1} x_{2} x_{3}$, а в качестве фоновых элементов - близкие по виду, но не входящие в искомый полином, например, $b_{1}+, b_{2} x_{1}+, b_{23} x_{1} x_{3}+, b_{13} x_{1} x_{2} x_{3}$. Целью выполнения данного задания является восстановление вида полинома.

Таким образом, особенностью ТВФ является их специализация: обеспечение контроля усвоения на уровне воспроизведения языковых выражений и специиально конструируемых наборов символов.

Второй важной возможностью, которую предоставляют ТВФ, является обучение. Компьютерная программа-оболочка [10] и, соответственно, разработанные на ее базе тесты, имеют функцию «верный ответ», которой может воспользоваться респондент после выполнения текущего задания. В этом случае на экран полностью выводится контролируемое языковое выражение. То есть материалы ТВФ являются самодостаточными для процесса обучения ввиду того, что в них содержатся вопросы и полные ответы на них. А наличие функции «верный ответ» позволяет респонденту сопоставить вопрос с верным ответом на него, что и является основным элементом процесса обучения. Многократное прохождение теста в режиме самоподготовки усиливает эффект обучения. Таким образом, наличие функции «верный ответ» и возможность многократного прохождения теста, полная объективность оценки и оперативность ее получения позволяют использовать ТВФ в качестве средства самообразования и индивидуального обучения.

Понятно, что разработанный тест не может использоваться как основное средство обучения и для приобретения глубоких знаний необходимо применять учебные материалы, раскрывающие суть контролируемых в задании языковых выражений. Однако, даже использование только ТВФ, приводит к устойчивому запоминанию контролируемых выражений.

Результаты тестирования студентов показывают, что осмысленное выполнение ТВФ (предусматривает самоанализ ответов с использованием функции «верный ответ») в количестве трех-четырех раз обеспечивает получение зачетной отметки даже студентами с очень низким начальным уровнем знаний. На рис. 3 показана диаграмма распределения количества попыток сдачи тестов $-N$ для достижения зачетной отметки (вне зависимости от ее значения). Объем выборки для каждого теста одинаков и представлен результатами тестирования 72 студентов. Как видно из диаграммы, с первой попытки тесты сдавали не менее половины всех студентов, с двух - не менее $95 \%$.

Вполне очевидно, что часть студентов при подготовке к тесту используют только материал контрольных заданий, и не привлекает другие учебные материалы, попросту заучивает. Фактически студенты, сдававшие более 2 раз, с большой вероятностью обучались в основном в процессе сдачи теста, что также подтверждает возможность использования ТВФ в процессе самообучения и индивидуального обучения.

Третьей основной возможностью ТВФ является стимулирование учебной деятельности (рис. 2). 
Применение ТВФ обеспечивает «тотальный» контроль всего учебного материала, задекларированного в цели теста. Например, при изучении курса «Планирование научных экспериментов» каждый студент в процессе выполнения двух тестов [3] отвечает на 60 теоретических вопросов. Понятно, что такой объем контроля невозможно провести традиционными средствами в отведенное учебным планом время.

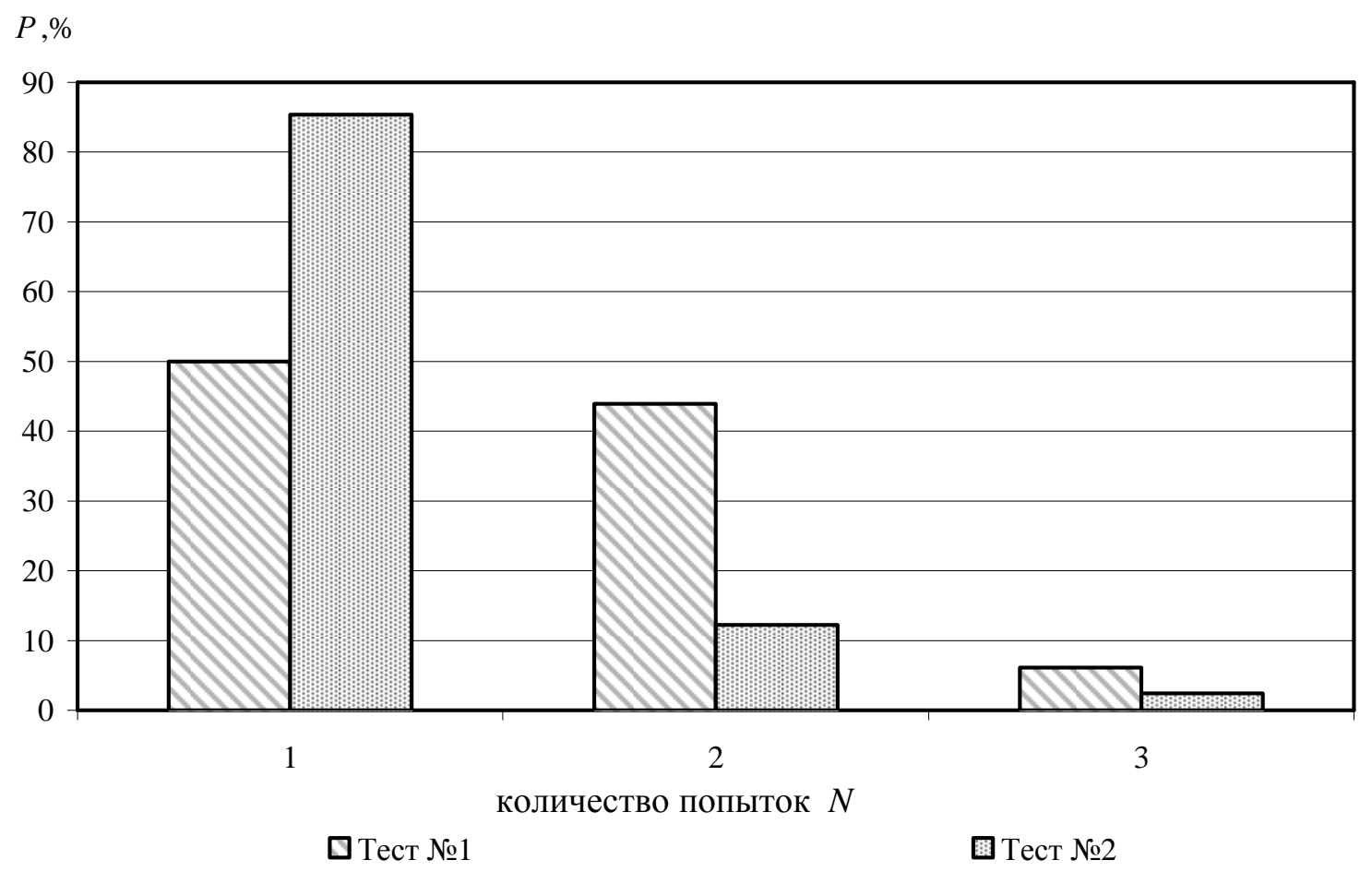

Рис. 3. Распределение количества попыток сдачи теста

В последнее время в силу протекающих социальных процессов значительная часть студентов стремится к минимизации своих затрат на получение диплома о высшем образовании. Понятно, что такой подход приводит к снижению уровня знаний. Поэтому когда они сталкиваются с системой контроля, которая вынуждает их изучать учебный материал, а не только «сдавать» учебный курс любыми средствами, возникают психологические конфликты.

При устном ответе одним из характерных типов поведения некоторых студентов в процессе контроля знаний является: произнести набор слов или фраз, близких по содержанию к требуемым и/или верных, но логически не связанных фраз, а потом ожидать реакцию преподавателя и, в качестве ответа на замечание, доказывать, что «я же это и говорил». Применение тестов данного класса исключает подобную ситуацию, так как программа обеспечивает четкость при выборе ответов.

Описанные ситуации приводят к негативной реакции студентов, ибо применение тестов «заставляет» студентов учится.

Отметим условия проведения зачетного тестирования: студентам, сдавшим первый раз на отметку «удовлетворительно» или «хорошо» предоставлялась возможность пересдачи еще один раз для улучшения отметки; студенты, получившие отметку «неудовлетворительно» сдавали до тех пор, пока не получали зачетную отметку. Данные возможности приветствовалась студентами. 
Таким образом, использование ТВФ в учебном процессе приводит к психологическому стимулированию учебной деятельности за счет обязательности контроля и возможности улучшения итоговой оценки.

Важным фактором стимулирования учебной деятельности является возможность получения отметки, целью достижения которой является внутренняя установка студента. ТВФ обеспечивает четкие границы объема знаний для каждой отметки.

На рис. 4 показана диаграмма, отражающая среднее количество попыток сдачи теста на отметку.

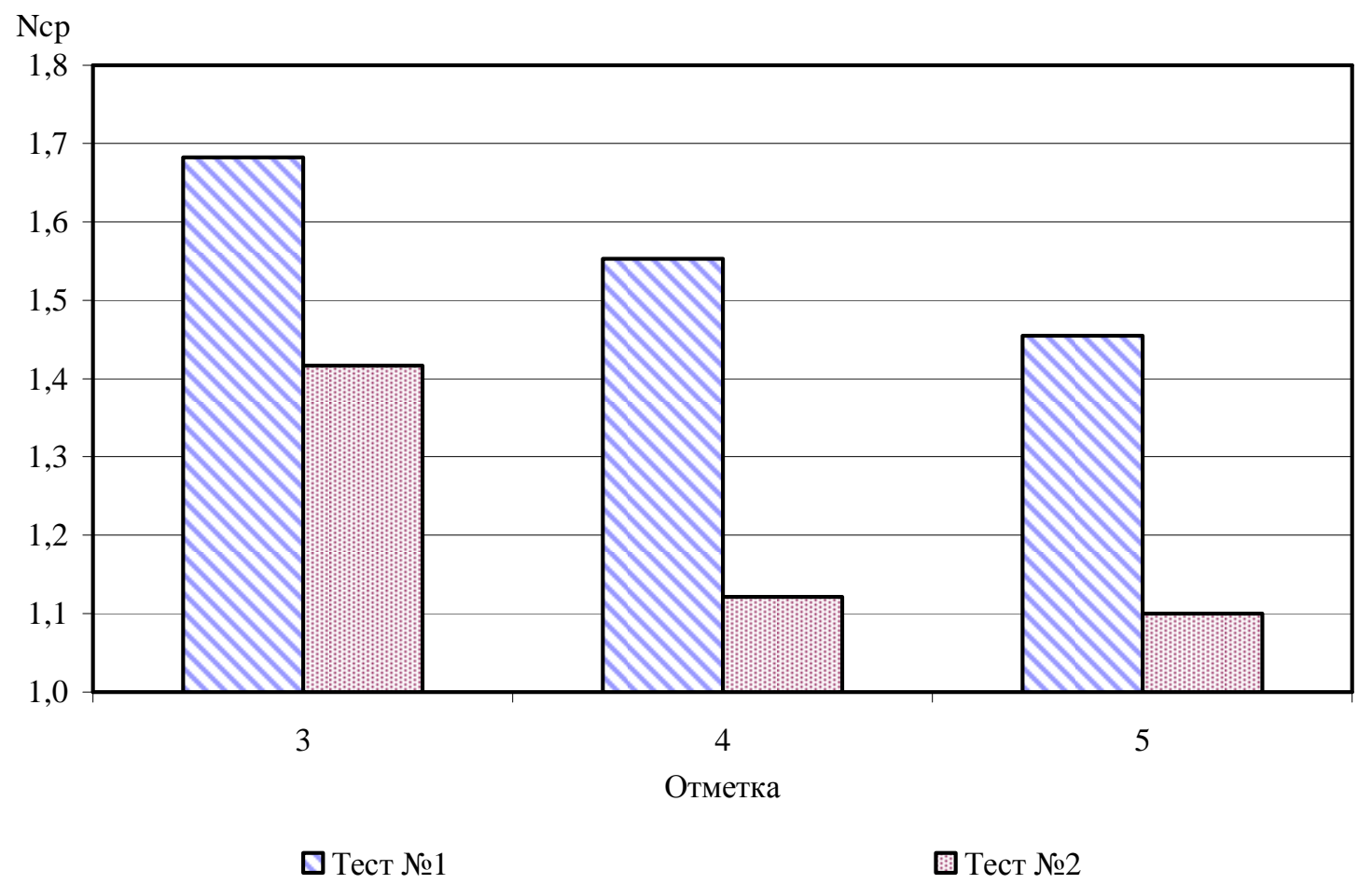

Рис. 4. Среднее количество попыток сдачи теста на отметку

Как видно из рис. 4, чем выше отметка, на которую претендует студент, тем меньшее количество попыток требовалось, а это значит, что студент лучше готовился к контролю, то есть применение ТВФ стимулирует учебную деятельность за счет объективности контроля и полной определенности контрольного материала.

\section{4. ВЫВОДЫ И ПЕРСПЕКТИВЫ ДАЛЬНЕЙШИХ ИССЛЕДОВАНИЙ}

1. Показано, что тесты с восстанавливаемыми фрагментами обеспечивают на современном уровне развития компьютерной техники оптимальные условия контроля языковых выражений на уровне воспроизведения.

2. Результаты экспериментов подтвердили педагогические возможности тестов с восстанавливаемыми фрагментами для контроля усвоения теоретического материала, обучения и стимулирования учебной деятельности студентов.

Материалы статьи могут являться основой для дальнейших исследований возможностей использования тестов с восстанавливаемыми фрагментами в учебном процессе, в частности, их аналитических возможностей. 


\title{
СПИСОК ЛИТЕРАТУРЫ
}

1. Васильев И. Б. Диагностика обученности и уровни усвоения знаний / И. Б. Васильев // Професійна освіта: теорія і практика : науково-методичний бюлетень. - 2002. - № 1-2 (15-16). - С. 51-69.

2. Педагогика / под ред. П. И. Пидкасистого. - М. : Педагогическое общество России, 2000. — 640 с.

3. Пєтков О. О. Діагностичні характеристики комп'ютерних тестів, які формуються за методом відновлюваних фрагментів [Електронний ресурс] / О. О. Пєтков // Інформаційні технології і засоби навчання. - 2013. — №1 (33). — Режим доступу : http://journal.iitta.gov.ua/index.php/itlt/article/ download/779/582.

4. Раков С. А. Педагогічні можливості тестів з математики формату SA / C. А. Раков // Комп’ютер у школі та сім’ї. - 2004. - № 1. - С. 14-18.

5. Использование тестов в учебном процессе. [Электронный ресурс]. - Режим доступа: http://testobr.narod.ru/3.htm. — Название с экрана.

6. Учебное пособие. [Электронный ресурс]. - Режим доступа: http://www.uch-posobie.ru/sozdaniekomp-yuternyh-testov/testovye-zadaniya-zakrytogo-tipa. - Название с экрана.

7. Пєтков О. О. Оцінка рівня засвоєння термінологічної системи обмеженої галузі знань [Електронний ресурс] / О. О. Пєтков // Інформаційні технології і засоби навчання. — 2012. — № 4. (30). — Режим доступу : http://journal.iitta.gov.ua/index.php/itlt/article/view/705/526.

8. Кузьмінський А. І. Тест навчальних досягнень особистості як засіб педагогічного вимірювання / А. І. Кузьмінський, В. І. Сфіменко. - Черкаси : Видавничий відділ Черкаського державного університету імені Богдана Хмельницького, 2002. — 64 с. — ISBN 966-7986-33-0.

9. Машбиц Е. И. Диалог в обучающей системе / Е. И. Машбиц, В. В. Андриевская, Е. Ю. Комисарова. — К. : Выща. шк., 1989. - 184 с. — ISBN 5-11-000190-1.

10. Петков А. А. Компьютерная программа "Компьютерная программа контроля уровня усвоения теоретического материала учебного курса "Теорема". Свидетельство о регистрации авторского права на произведение № 28537 от 24.04.2009. Государственный департамент интеллектуальной собственности Министерства образования и науки Украины.

11.Петков А. А. Совершенствование контроля знаний при подготовке специалистов электротехнического профиля / А. А. Петков // Вісник Національного технічного університету "Харківський політехнічний інститут". Збірник наукових праць «Проблеми удосконалення електричних машин і апаратів. Теорія і практика». — Х. : НТУ "ХПІ". — 2010. — № 36. — С. 94 98.

12. Егоров А. Е. Исследование устройств и систем автоматики методом планирования эксперимента / Егоров А.Е., Азаров Г. Н., Коваль А. В. ; под ред. В. Г. Воронова. - Х. : Вища шк. Изд-во при Харьк. ун-те, 1986. - 240 с.

Материал поступил в редакиџю 23.08.2013 г.

\section{ПЕДАГОГІЧНІ МОЖЛИВОСТІ ТЕСТІВ ІЗ ВІДНОВЛЮВАНИМИ ФРАГМЕНТАМИ}

\author{
Пстков Олександр Олександрович \\ старший науковий співробітник, доктор технічних наук, провідний науковий співробітник, доцент \\ кафедри «Інженерна електрофізика» \\ Науково-дослідний та проектно-конструкторський інститут «Молнія» Національного технічного \\ університету «Харківський політехнічний інститут» м. Харків, Україна \\ apetkov@yandex.ru
}

\begin{abstract}
Анотація. У статті розглянуті педагогічні можливості тестів, які формуються за методом відновлюваних фрагментів. Проведено аналіз взаємозв'язку тестів даного типу з іншими типами тестів. Показано можливість застосування тестів із відновлюваними фрагментами для контролю засвоєння на рівні відтворення: мовних виразів, представлених у текстовому форматі, набору символів, що мають значеннєве навантаження, а також мовних виразів, які описують графічно представлені об'єкти. Наведено результати експериментів, які підтверджують педагогічні можливості використання тестів 3 відновлюваними фрагментами для контролю засвоєння теоретичного матеріалу, навчання й стимулювання навчальної діяльності студентів.
\end{abstract}

Ключові слова: тест із відновлюваними фрагментами; педагогічні можливості; мовні вирази; контроль засвоєння; навчання; стимулювання навчальної діяльності. 


\title{
THE EDUCATIONAL OPPORTUNITIES OF TESTS WITH THE RESTORED FRAGMENTS
}

\author{
Alexandr A. Petkov \\ senior researcher, Doctor of technical sciences, chief researcher, associate professor of the Department \\ "Engineering Electrophysics" \\ Design -\&- Research Institute "Molniya" of National Technical University "Kharkov Polytechnic Institute", \\ Kharkov, Ukraine \\ apetkov@yandex.ru
}

\begin{abstract}
The article considers the educational opportunities of the tests, which are formed by the method of the restored fragments, the analysis of the relationship tests of this type with other types of tests. It is shown the possibility of applying the tests with the restored fragments for checking the quality of learning at the level of playback: language expressions presented in text format, a set of characters that have meaning and language expressions that describe graphically displayed objects. The results of experiments that confirm the educational opportunities of the use of tests with the restored fragments to control the learning of theoretical material, education and stimulation of educational activity of students, are presented.
\end{abstract}

Keywords: test with the restored fragments; educational opportunities; linguistic expressions; control of mastering; training; promotion of educational activities.

\section{REFERENCES (TRANSLATED AND TRANSLITERATED)}

1. Vasil'ev I. B. Diagnostics of train and levels of mastering digestion of knowledge / I. B. Vasil'ev // Profesiina osvita: teoriia i praktyka. Naukovo-metodychnyi biuleten. — 2002. — № 1-2 (15-16). — S. 51-69. (in Russian)

2. Pedagogy / pod red. P. I. Pidkasistogo. - M. : Pedagogicheskoe obshhestvo Rossii, 2000. — 640 s. (in Russian)

3. Petkov O. O. Diagnostic characteristics of the computer tests formed by method of restored fragments [online] / O. O. Petkov // Informacijni texnolohiyi i zasoby navchannya. — 2013. — № 1 (33). Available from: http://journal.iitta.gov.ua/index.php/itlt/article/dovnload/779/58. (in Ukrainian)

4. Rakov S. A. Pedagogical possibilities of tests are from mathematics of format SA / S. A. Rakov // Kompiuter u shkoli ta simi. — 2004. — № 1. - S. 14-18. (in Ukrainian)

5. The use of tests is in an educational process.[online]. - Available from : http://testobr.narod.ru/3.htm. Nazvanie s jekrana. (in Russian)

6. Train aid [online]. — Available from : http://www.uch-posobie.ru/sozdanie-komp-yuternyhtestov/testovye-zadaniya-zakrytogo-tipa. — Nazvanie s jekrana. (in Russian)

7. Petkov $O$. O. Estimation of mastering level of terminological system of theknowledge limited field [online] / O. O. Petkov // Informatsiini tekhnolohii i zasobynavchannia. — 2012. — № 4 (30). Available from : http://journal.iitta.gov.ua/index.php/itlt/article/view/705/526. (in Ukrainian)

8. Kuzminskyi A. I. Test of educational achievements of personality as means of the pedagogical measuring / A. I. Kuzminskyi, V. I. Yefimenko. - Cherkasy : Vydavnychyi viddil Cherkaskoho derzhavnoho universytetu imeni Bohdana Khmelnytskoho, 2002. - 64 s.— ISBN 966-7986-33-0. (in Ukrainian)

9. Mashbic E. I. Dialogue in teaching system / E. I. Mashbic, V. V. Andrievskaja, E. Ju. Komisarova. - K. : Vyshha. shk., 1989. - 184 s. — ISBN 5-11-000190-1. (in Russian)

10. Petkov A. A. Computer program: "Computer program of control of level of digestion of theoretical material of educational course "Teorema". Svidetel'stvo o registracii avtorskogo prava na proizvedenie \# 28537 ot 24.04.2009. Gosudarstvennyj departament intellektual'noj sobstvennosti Ministerstva obrazovanija i nauki Ukrainy. (in Russian)

11. Petkov A. A. Perfection of the knowledge control at preparation of electrotechnical profile specialists / A. A. Petkov // Visnyk Natsionalnoho tekhnichnoho universytetu "Kharkivskyi politekhnichnyi instytut". Zbirnyk naukovykh prats. Problemy udoskonalennia elektrychnykh mashyn i aparativ. Teoriia i praktyka. — Kh. : NTU "KhPI". — 2010. — № 36.— S. 94-98. (in Russian)

12. Egorov A. E. Study of devices and automation systems using design of experiments / Egorov A. E., Azarov G. N., Koval' A. V. ; pod red. V. G. Voronova. - Har'kov : Vishha shk. Izd-vo pri Har'k. un-te, 1986. - 240 s. (in Russian) 